\title{
Role of Advanced Simulation in Undergraduate and Postgraduate Medical Education

\section{Abstract}

Medical simulations are effective education complements for medical training, demonstrating effective learning, level of participation, and improvement in knowledge, skills and attitudes.

In undergraduate medical education, simulation provides the potential for valid, cost-benefit teaching and assessment of clinical skills, especially clinical reasoning skills, bridging the gap between theory and practice. Simulation as a training tool in postgraduate medical training is a practical method to provide a kind of educational realistic significance for practicing specialty in order to improve quality of care and patient safety. In particular, simulation is an excellent opportunity to implement reports of security which can be considered a true strategy in order to minimize clinical risk and ensure appropriate levels of quality in daily clinical practice.

Medical simulations, early clinical contact, undergraduate medical education, postgraduate medical training.

\section{Keywords}

\author{
Vincenzo Fodale ${ }^{1,2}$ \\ Olivia Penna ${ }^{1}$, \\ Antonio Amato1, \\ Rosario Bruno", \\ Vincenzo Francesco Tripodi ${ }^{3}$, \\ Eugenio G. Vadalà ${ }^{3}$, \\ Giuseppe Guzzo ${ }^{3}$, \\ Maria Gabriella D'Arrigo ${ }^{3}$, \\ Carolina Giordano ${ }^{3}$, \\ Maria Rosa Signer ${ }^{1}$, \\ Francesco Squadrito ${ }^{4,5}$
}

1 Skill-Lab for Simulation-Based Medical Education, Degree Course in Medicine and Surgery, University of Messina, Messina, Italy.

2 Department of Neuroscience, University of Messina, Messina, Italy.

3 Anesthesiology Residency Program at the University of Messina, Messina, Italy.

4 Dean of Degree Course in Medicine and Surgery, University of Messina, Messina, Italy.

5 Department of Clinical and Experimental Medicine, University of Messina, Messina, Italy.

\section{Contact information:}

In patients undergoing anesthesia and those hospitalized, a high level of security is required and expected in the operating theatre, perioperative care and intensive care units (ICU). [1, 2] However, it has been calculated that $80 \%$ of adverse events seem related to preventable errors. [3] To improve patient safety, detection and risk analysis should lead to the development of preventive strategies. [4, 5].

Some of these strategies, allowing a better understanding of the complexity of the system of health care, have allowed the partial redesign and reorganization of care systems around the complex microcosm of clinical care. Behind the traditional concepts of risk reduction (e.g. by pursuing specific guidelines), new strategies could

\section{Vincenzo Fodale.}

Chief of Skill-Lab, Simulation-Based Medical Education.

Tel: (39) 0902212450.

Address: SKILL-LAB, University of Messina. Policlinico Universitario, Pad. G, Piano 5. Via C. Valeria. 98125 Messina, Italy.

Ævfodale@unime.it 
be applied to minimize the negative impact of human factors on patient safety. $[4,5]$ In this context, simulation provides skills and experience in solving specific situations included in a realistic scenario, facilitating the transfer of cognitive, psychomotor and affective capacity within daily clinical practice (in practice, proper communication within the team), thus helping to improve behavior in critical situations. [6, 7]

Simulation in anesthesia and intensive care (AIC) is a practical method to provide a kind of educational realistic significance for practicing anesthesiologists in order to improve the quality of care and patient safety. In particular, in AIC, simulation is an excellent opportunity to implement those reports of security which can be considered as a real strategy to minimize clinical risk. [8, 9]

The paper reviews simulators used in healthcare, focused on the range of application, main benefits and educational level of students. It is aimed to promote the dissemination of computer technologies to support the field of medicine, using simulators.

\section{Simulation in undergraduate medical student education}

Early clinical contact $\&$ advanced medical simulation: an innovative integrated education program for medical students

Early clinical contact is a particularly important curricular innovation that allows students of the first years of undergraduate medical schools to have early patient contact experiences. [10, 11] Medical simulations are effective education complements for medical training, demonstrating effective learning, level of participation, and improvement in knowledge, skills and attitudes. [12, 13] In undergraduate medical education, simulation provides the potential for valid, cost-effective teaching and assessment of clinical skills, especially clinical reasoning skills. [14, 15] In particular, student acceptance of virtual patients is high, with greater acceptance in pre-clinical (first and second-year) compared with clinical (fourth-year and further) medical students: therefore, medical simulation appears to be particularly well suited for learning and assessment purposes in junior medical students who have not yet had significant clinical contact. $[15,16]$

An educational program that integrates early clinical contact and medical simulation appears therefore to be appropriate and innovative (Figures 1 and 2).

Lesson of anesthesia for medical students in the operating room: effectiveness of interactive simulation training as support tool to traditional frontal teaching

Frontal teaching is used for the acquisition of theoretical knowledge through a determined learning style and is suggested in cases where the participants in training are devoid of relevant information with respect to presented content. [17] Commonly, anesthesiology is part of the sixth year of undergraduate medical training. In particular, the learning of general anesthesia, because of specialist contents and pharmacology issues, may prove particularly difficult. The use of advanced simulation-based teaching in the undergraduate's medical education improves learning and bridges the gap between theory and practice. $[18,19]$ In our institution, all medical students allocated to the anesthesia rotation are invited to take a facultative elective course in anesthesiology as an integration to obligatory frontal teaching. Medical students, in small groups, attend an interactive simulation workshop in an operating room scenario with learning goals directed towards induction, maintenance, and emergence from general anesthesia (Figures 3 and 4).

\section{Use of simulators in pharmacology}

Administration of drugs requires, in addition to knowledge of pharmacologic properties, the basic 
Figure 1 and 2: At the University of Messina Medical School an innovative integrated educational vertical program of "Early Clinical Contact \& Advanced Medical Simulation" has been created and added to the curriculum of first- and second-year undergraduate medical students.
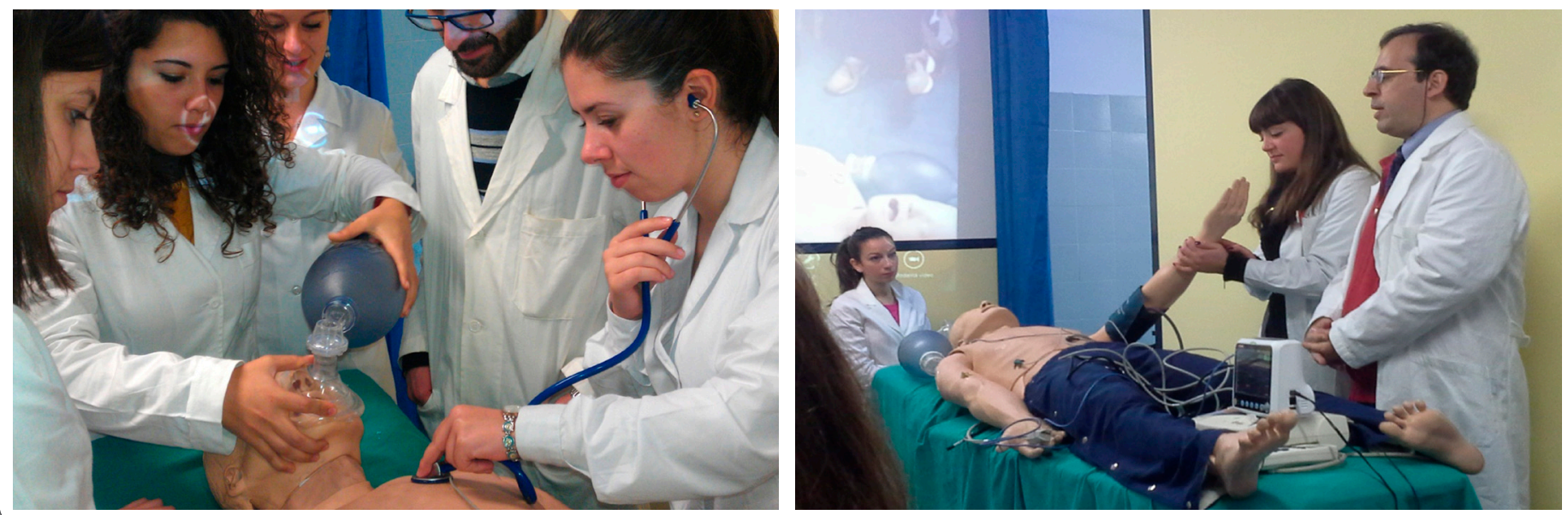

Figure 3 and 4: Medical students at the University of Messina Medical School attend an interactive simulation workshop in an operating room scenario with learning goals directed towards induction, maintenance, and emergence from general anesthesia.
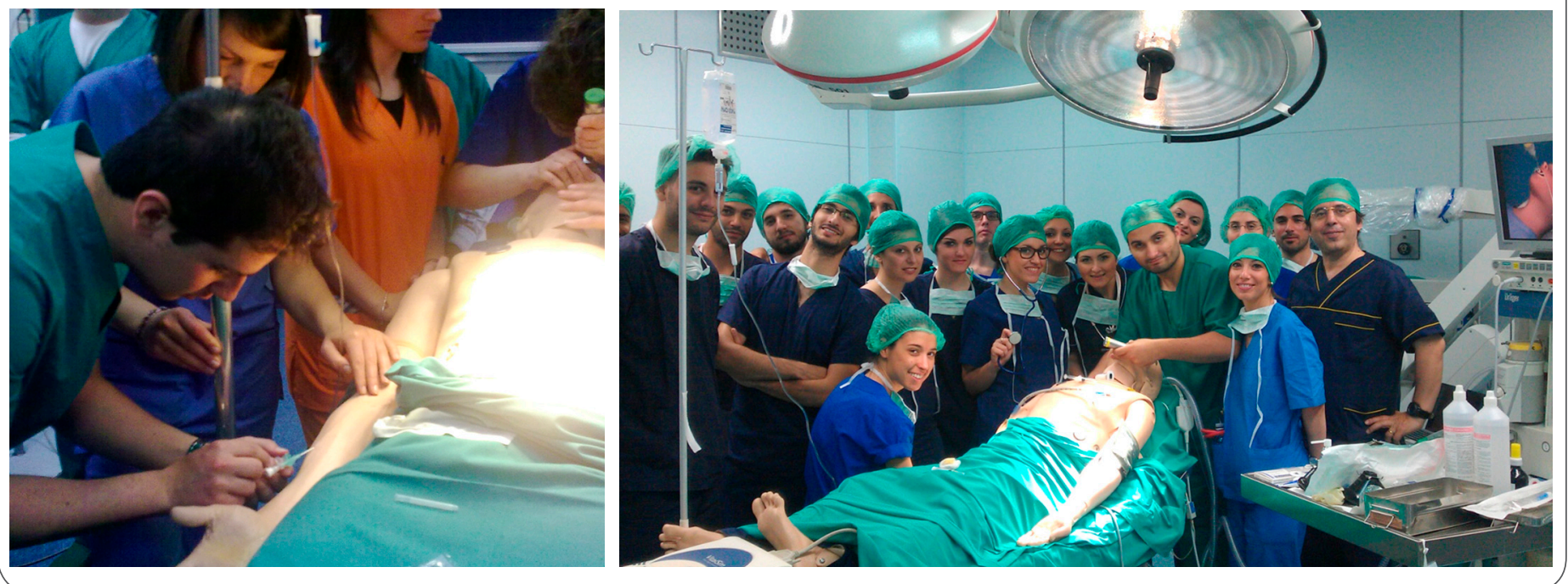

skills of vital-sign checking and physical assessment to evaluate patient condition/drug efficacy and prevent adverse reactions to drugs: mastering these techniques may allow medical students to determine the efficacy of a drug and adverse reactions. [20] To promote the acquisition of these skills, it is possible to prepare simulation programs with an emergency-care simulator which facilitate the reproduction of excess-dose drug administration/ condition changes. Although further research is needed to determine whether the use of simulation in Pharmacology curriculum is equivalent or superior to other teaching methods, students' enthusiasm for learning in a simulated environment where they can safely apply patient care skills make this technology worth exploring. [21]

High fidelity patient simulators are being used with increasing frequency in the pharmacological training of medical students as they enable students to develop and refine medical competency 
in a non-threatening, safe environment. Therefore, high fidelity patient simulators may be a valuable tool in helping to improve pharmacology knowledge in medical students, and may also be beneficial in other areas of study where interactive learning could assist in evoking emotional realism while also enhancing critical thinking and acquisition of knowledge, thereby facilitating the transition from theory to practice. [22]

However, in another study, comparing low- and high-fidelity simulation to measure student ability to administer an injection, student self-perceived levels of confidence, proficiency, and anxiety were not dependent on the type of simulation training used. [23]

\section{Simulation in pediatric training}

Simulation-based pediatric medical education has become popular in undergraduate, as well as postgraduate, training.

In North American medical schools, simulationbased education is commonly used for instruction during pediatric undergraduate medical education for third- and fourth-year medical students, and it is considered necessary to meet the requirements of the Liaison Committee on Medical Education. [24] Practice in the pediatric simulation setting may also include neonatal intubation performance, [25] and management of children with febrile convulsion. [26]

However, in many academic institutions, simulation-based training for undergraduate medical student has usually been principally focused on an adult population, minimizing the importance of this area of simulation, not necessarily due to lack of interest in providing education, but rather, probably related to proper manikin and instructor availability. Basic Life Support, Advanced Cardiac Life Support, and Pediatric Advanced Life Support, integral parts of emergency resuscitative care training, are therefore usually reserved for postgraduate students and residents.
A recent survey demonstrated that students feel unprepared to respond to cardiac arrests and resuscitations in a pediatric context: they feel that this training is needed in their curriculum and would possibly enhance perceived comfort levels and willingness to participate in resuscitations. [27] Providing progressive simulation-based pediatric education for undergraduates could be one small step for Medical Schools, but a giant leap for medical students.

\section{Simulation in postgraduate medical training}

The benefits of simulation as a training tool in postgraduate medical training may be summarized as follows: 1) no risks for the patient; 2) application to common situations, routine procedures, as well as rare events; 3) possibility of learning and performing maneuvers or using complex tools; 4) test the ability to apply decision-making, communication and group dynamics; 5) possibility of individual and/or in group discussion, evaluation of therapeutic interventions carried out, also using an audio-video playback (the so-called debriefing session).

Commonly, the cycle of medical training involves study carried out on textbooks. However, although theoretical knowledge represents the cultural background for the future physician or physician in training, it is good to consider that medicine is an eminently practical discipline. Particularly in the hospital, patient management is often concerted with other healthcare professionals, working in the same or in other departments. It is obvious how this logic entails the necessity of dialogue between healthcare workers with the purpose of forming a team able to always guarantee the same quality of treatment regardless of the staff that is managing the patient. It is equally evident that this important part of medical education can hardly be taught during the degree course but is essentially lacking during postgraduate school where the "what to 
do" in various clinical situations is the preferred aim of the teaching, while the "how to do" is often left to the initiative of the individual. This implies that both the recently graduated physician, as well as the specialist, have the difficulty of proper integration into the reality of a hospital department, where communication among professional figures appears to be one of the greatest difficulties in the realization of the team.

The only answer to these difficulties is the simulation of typical clinical cases (simple situations, complex or rarely seen), or application of specific rules that must be faced by various professionals, to emphasize integration among healthcare providers. However, the overall success of this innovative methodology should be based on absolute realism, not only as a simple "theoretical case study", but also with a "place" where to perform the clinical case. In other words, a location dedicated to the simulation is necessary, which must be as similar as possible to that in which the learners work, also in the furnishings. This site is commonly referred to as "center or laboratory of simulation " (the socalled simul-center or simul-lab), an environment in which it is possible to study professional areas and methods to improve training, and create training courses for different professions with a proper impact (Figures 5 and $\mathbf{6}$ ).

Finally, simulators have applications not only for teaching undergraduate and postgraduate medical students, or in the training of doctors and health staff working in the field of specialty, but are also becoming, along with the lines proposed in the United States by the American Society of Anesthesiologists, a tool for the assessment of attitudes and skills, attested subsequently by a certificate issued by a scientific society, $[28,29]$ although this use has sometimes been criticized. [30]

The validity and enforceability of assessment tools for measuring performance during the processes of simulation in anesthesia have been the subject of intensive studies in the past, investigating the validity and quality of the assessment systems and concluding that the introduction of test -based simulators for certification or re-certification of anesthesiologists could be entirely premature. [31-33]

\section{Which simulator?}

The simulators specifically designated for anesthesia and resuscitation, some of which use highly sophisticated technologies, are rapidly undergoing

Figure 5 and 6: Simulation workshop in an operating room for the Anesthesiology Residency Program at the University of Messina Medical School.
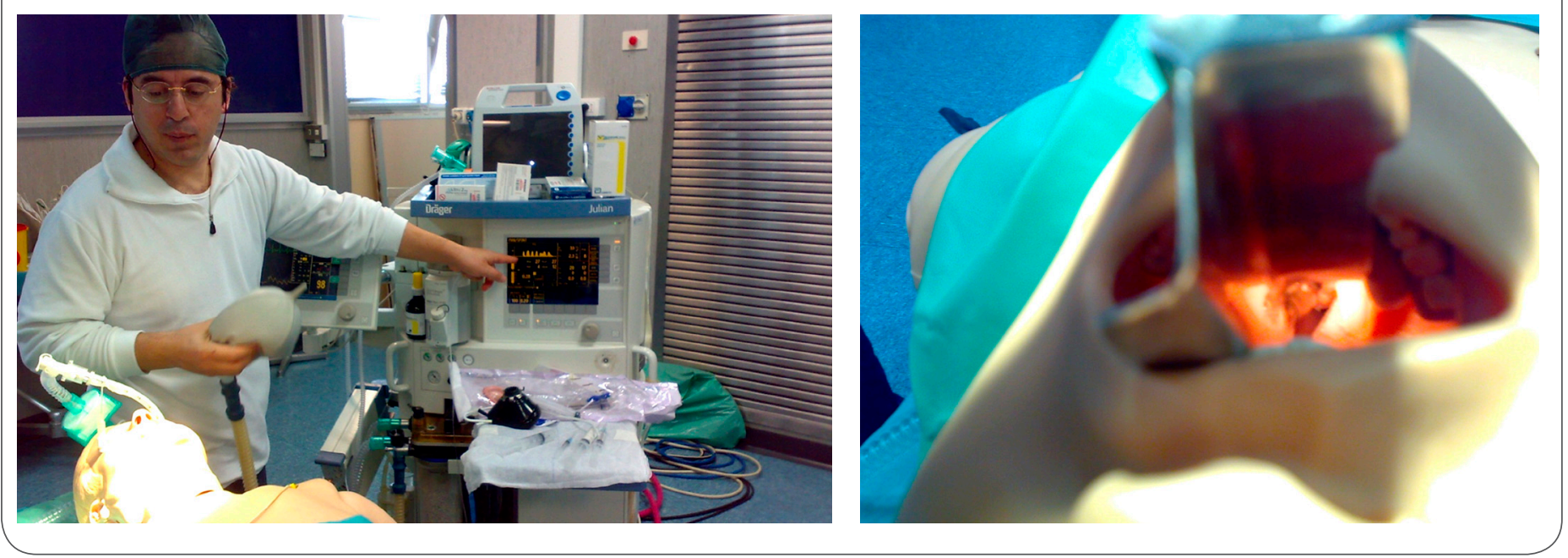
widespread distribution. [34, 35] Those who decide to create a simulation system devoted to the teaching of AIC have a wide choice, ranging from handmade devices to those extremely close to the reality of clinical practice regarding characteristics and fidelity, passing through intermediate solutions at an affordable cost according to locations, in an ever-expanding, evolving market. $[36,37]$ In particular, over the last decade, there has been a distinct orientation towards the use of human-size mannequin-simulators, which seem to provide for a unique, very realistic experience: "the management is very similar to what you feel being next to a patient in everyday clinical practice anesthesiology". [38] In fact, simulators at a scale of 1:1 appear to increase not only learning abilities but also those of execution in clinical practice [39] and are the best tool to improve and teach a more rapid decision-making capacity. For over a decade, in Germany, the Anesthesiology and Intensive Care Medicine Society has stated that centers for teaching anesthesia must be equipped with humansize simulation systems. [7]

The basic features for a successful training program that uses human-size simulators are essentially represented by a suitable logistics infrastructure, appropriate materials, participation of instructors with specific training courses, and an instructorstudent ratio as close as possible to the ideal value of 1:3, equivalent to that suggested for correct teaching at the bedside. [40] Typical scenarios of simulation in anesthesia can be represented by common management and daily problems that the specialist anesthetist faces (e.g. induction of anesthesia, difficult intubation, postoperative hypotension, management of trauma, cardiopulmonary resuscitation, etc.), or related to the sub-specialties of the discipline (e.g. simulators for regional anesthesia).

Regional anesthesia simulators offer optimal visualization of anatomical structures, and are considered a crucial element of training for optimal performance in the realization of the block, but also a primary factor in safety and patient satisfaction. [41, 42] These simulators allow doctors, AIC specialists, but also surgeons, to be able to practice techniques of regional anesthesia in a similar way to real clinical practice.

\section{Simulators of drugs: an example from anesthesiology training}

Simulators of drugs (drug administration simulators) are a useful garrison, teaching clinical pharmacology during anesthesiology training. It is well recognized that a deep understanding of doseresponse interrelationships is necessary to optimize the effectiveness of anesthetics agents minimizing adverse effects. [43] However, with the exception of end-tidal concentration of inhalational anesthetics, it is still not possible to obtain, in real time and in a continuous manner, the value of concentrations of drugs administered (as in the case of intravenous anesthetics). As a consequence, administration of the many anesthetics drugs is still bound to standard criteria according to general guidelines that do not take into account individual pharmacokinetic and pharmacodynamic modifications. Since it is the belief that the introduction of these principles in medical training of AIC would lead to a significant improvement in the level of patient care and safety, development and the introduction of simulators that take multiple individual parameters into account for that patient (age, weight, height, body mass, etc.) appears highly desirable and welcome. [43, 44] The approach with these types of simulators is valuable in the study of drug interactions between drugs, when the simulation must reproduce the many interactions resulting from the simultaneous or sequential administration of anesthetics, as commonly occurs in clinical practice. [44, 45] Experimental studies that used simulator administration of drugs led to the creation of Target Controlled Infusion (TCI) anesthesia, today widely used in clinical practice, the principle of which is based on algorithms co- 
rrected by means of some parameters specific to that patient, and which provide, theoretically but with good approximation, the concentration of a drug to its site of effect (e.g. concentration in the central nervous system of hypnotic and analgesic drugs administered).

\section{Innovation and research are keywords for better quality in clinical simulation}

Medical training by means of the use of simulation techniques is suitable for the optimization of processes and helps to ensure appropriate levels of quality in daily clinical practice. [46] The American Society of Anesthesiologists believes that physicians in training, as well as specialists in AIC, can benefit from participation in programs and courses based on simulation techniques of high quality that promote patient safety, clinical ability of work groups in preventing and treating critical events, and also the maintenance of experience gained in specific areas. [47, 48] Improvement of the quality of the simulation could, according to some, undergo a standardization of simulation, in which all programs should use the same scenario in an homogeneous and reproducible manner, allowing subsequent rapid updates (standardization of simulation). If the simulation must be used for certification of practice in anesthesia, the process of simulation standardization is inevitable and cannot be postponed.

Accreditation of the structure seems to be a good choice, but this must be done in a very professional manner or accreditation itself could, in a short time, quickly lose credibility and meaning. Without doubt, we need to stress the importance and professionalism of the instructor, who should be able to document his experience in the simulation: however, the documentation of the experience of the instructor can not be considered a valid parameter for measuring competence. [48] Doubts also exist on the possible quality of the education received in simulation courses where teaching is carried out in a repetitive manner and without an update on the part of the instructors in the discipline, where developments and innovation in the field of anesthesia and sciences education take place continuously and very rapidly.

One of the main limitations of the simulation could be ascribed to the fact that performance during the simulation process might, in absolute, not be a good indicator of performance that will occur in a real situation (clinical practice). However, it is the widespread belief that performance during advanced simulation is truly comparable with the real one.

Important factors such as performance anxiety of the participant to the simulation must be considered. $[46,49]$ Although the goal of the process is learning and assessment, the mechanism of simulation is potentially anxiety-inducing for most individuals, with high points in susceptible individuals. $[48,49]$ The main factors of anxiety would consist of the possibility of facing scenarios never seen in their clinical practice, from knowing that the simulation process will be recorded and will then be reviewed and possibly judged and criticized, and by the fact of having beside them the other participants, who are almost always co-workers, and who will also be involved in the revision of the service provided. The individual should, however, more than anything else, look inside himself and not feel rebuked by the instructor or by other participants. Those who work in the field of education know how crucial the role of the instructor or facilitator is in reducing or preventing these negative emotions in participants, emphasizing that individual assessments are not made, and trying to convince the participants to react in a positive way; lessons are never boring or repetitive, but intellectual stimulants guaranteeing the acquisition of theoretical knowledge, improved ability to work in a team, and the internalization of technical practices in a controlled environment, in absolute security. Working in the field of simulation certainly 
requires dedication and love for this particular training method. But while passion is necessary for the activity of an educator, this is not sufficient to ensure competence for this role; it should also incorporate background culture and experience, and not least the ability to interact in an appropriate manner with participants in the simulation, with an educational and constructive spirit.

\section{Conclusions}

Simulation-based training is an exemplary solution for addressing the dynamic medical environment of today, and exceeds traditional didactic and apprenticeship models in terms of speed of learning, amount of information retained and capability for deliberate practice. [50] Simulation techniques can provide the skills training to solve specific problems in a virtual scenario, although completely realistic, facilitating cognitive and psychomotor transfer within daily clinical practice and improving behavioral skills in critical situations or in any case of danger. $[7,51]$

The benefits of incorporating specialty-oriented simulation training within medical schools are vast: simulators are capable of providing a highly educational and realistic experience for medical students within a variety of speciality-oriented teaching sessions, suggesting to incorporate simulators into the preclinical and clinical stage of undergraduate medical education. [52] Early clinical contact for medical students in the pre-clinical curriculum, aimed to teach communication skills integrated with practical clinical skills, improves student knowledge, efficiency and confidence, which may transfer to clinical practice with improved patient care and safety. [53] Adoption of simulators into medical school education programs has shown great promise and has the potential to revolutionize modern undergraduate education. [53] Postgraduate students and residents perceive that their experiences in earlier similar simulations positively affected their performances during emergencies. [54] The use of high fidelity simulation improves residents perceived understanding of and perceived ability to perform uncommon and more technically challenging procedures. [55] A progressive program that strategically combines simulation modalities provides a cost-effective solution. [56]

The concept of simulation must be interpreted as a "global approach". The goal is to highlight the consequences of errors or incorrect behavior, through evidence, and provide a line of conduct which, when applied in the reality of events, can lead to increased patient safety and satisfaction of clinical operator. [3] Simulation may also be used to increase the efficiency of training, allowing students to gain experience with special clinical situations and also rare complications, being able to repeat the opportunity to practice endlessly, without any risk for the patient. [57]

Simulation has deservedly gained a leading role in teaching and among the methods of training in the field of medical disciplines, further outlining the importance of the human factor in the occurrence of potentially critical situations. $[40,58]$ In conclusion, simulation is a unique and innovative medium of instruction for medical training, full of potential, and essential to the formation, growth and maturation of the student. It is truly important to provide all undergraduate and postgraduate medical schools with a simulation center or laboratory with suitable technology and preparation of instructors, in the certainty that this will contribute to patient safety and, ultimately, save many lives. 


\section{Author's Contributions}

VF conceived, designed, conducted the literature review and drafted the manuscript. OP, $A A, R B, V F T$, EGV, GG, MGA, CG, MRS, FS revised and corrected the manuscript. All authors were equally involved in reading and approving the final manuscript.

\section{Conflicts}

The authors declare no competing interests

\section{Funding}

None

\section{Acknowledgements}

No

\section{References}

1. Sevdalis N, Hull L, Birnbach DJ. Improving patient safety in the operating theatre and perioperative care: obstacles, interventions, and priorities for accelerating progress. $\mathrm{Br} J$ Anaesth. 2012;109 Suppl 1: i3-i16.

2. Rall M, Dieckmann P. Safety culture and crisis resource management in airway management: general principles to enhance patient safety in critical airway situations. Best Pract Res Clin Anaesthesiol. 2005;19: 539-57.

3. Bosse G, Schröder T, von Heymann C, Spies C. Berliner Simulations training (BeST) -the concept of anesthesia simulation. Anasthesiol Intensivmed Notfallmed Schmerzther. 2007; 42: 740-4.

4. Vincent C, Burnett S, Carthey J. Safety measurement and monitoring in healthcare: a framework to guide clinical teams and healthcare organisations in maintaining safety. BMJ Qual Saf. 2014; 23(8): 670-7.

5. Grube C, Schaper N, Graf BM. Man at risk. Preventive strategies and risk management for patient safety. Anaesthesist. 2002;51:239-47.

6. Sullivan DL, Chumbley C. Critical thinking a new approach to patient care. JEMS. 2010; 35(4): 48-53.

7. Timmermann A, Eich C, Nickel E, Russo S, Barwing J, Heuer JF, et al. Simulation and airway managemen. Anaesthesist. 2005; 54: 582-7.
8. Chilkoti G, Mohta M, Wadhwa R, Saxena AK. Problem-based learning research in anesthesia teaching: current status and future perspective. Anesthesiol Res Pract 2014; 263948.

9. Rall M, Dieckmann P, Manser T, Zieger J, Unertl K. Simulation as strategy for risk minimizing in anesthesia. Anasthesiol Intensivmed Notfallmed Schmerzther. 2004; 39: 240-7.

10. Iwata K, Gill D. Learning through work: clinical shadowing of junior doctors by first year medical students. Med Teach 2013; 35(8): 633-8.

11. Goldie J. Teaching professionalism in the early years of a medical curriculum: a qualitative study. Med Educ. 2007; 41: 610-7.

12. Parekh A, Thorpe T. How should we teach undergraduates in simulation scenarios? Clin Teach. 2012; 9(5): 280-4.

13. Issenberg SB. Features and uses of high-fidelity medical simulations that lead to effective learning: a BEME systematic review. Med Teach. 2005; 27: 10-28.

14. Moreno-Ger P, Torrente J, Bustamante J, Fernández-Galaz C, Fernández-Manjón B, Comas-Rengifo MD. Application of a lowcost web-based simulation to improve students' practical skills in medical education. Int J Med Inform. 2010; 79(6): 459-67.

15. Gesundheit N. The use of virtual patients to assess the clinical skills and reasoning of medical students: initial insights on student acceptance. Med Teach. 2009; 31: 739-42.

16. Oliven A, Nave R, Hasson-Gilad DR, Baruch A. Medical students' views on the use of virtual patients for teaching and assessment of clinical knowledge and reasoning. Harefuah. 2013; 152(5): 257-61.

17. ISTUD Foundation. Frontal Lesson. c2014. Available from: http:// www.istud.it/en/faculty/metodi_didattici/Lezione_frontale.aspx

18. Weller JM. Simulation in undergraduate medical education: bridging the gap between theory and practice. Med Educ. 2004; 38: 32-8.

19. Hallikainen J. Teaching anaesthesia induction to medical students: comparison between full-scale simulation and supervised teaching in the operating theatre. Eur J Anaesthesiol. 2009; 26: 101-4

20. Tokunaga J, Takamura N, Ogata K, Setoguchi N, Matsuoka T, Sato K. Preparation of simulation programs regarding excessdose drug administration and acute-phase condition changes and its evaluation by students. Yakugaku Zasshi. 2011; 131(4): 655-9.

21. Ray SM, Wylie DR, Shaun Rowe A, Heidel E, Franks AS. Pharmacy student knowledge retention after completing either a simulated or written patient case. Am J Pharm Educ. 2012; 76(5): 86

22. Halm BM, Lee MT, Franke AA. Improving toxicology knowledge in preclinical medical students using high-fidelity patient simulators. Hawaii Med J. 2011; 70(6): 112-5.

23. Skoy ET, Eukel HN, Frenzel JE. Comparison of low- and higherfidelity simulation to train and assess pharmacy students' injection technique. Am J Pharm Educ. 2013; 77(2): 33. 
24. Vukin E, Greenberg $R$, Auerbach $M$, Chang L, Scotten $M$, Tenney-Soeiro $R$, et al. Use of simulation-based education: a national survey of pediatric clerkship directors. Acad Pediatr 2014; 14(4): 369-74

25. Ernst KD, Cline WL, Dannaway DC, Davis EM, Anderson MP, Atchley $C B$, et al. Weekly and consecutive day neonatal intubation training: comparable on a pediatrics clerkship. Acad Med. 2014; 89(3): 505-10

26. Kim SJ, Oh J, Kang KA, Kim S. Development and evaluation of simulation-based fever management module for children with febrile convulsion. Nurse Educ Today. 2014; 34(6): 1005-11.

27. Pillow MT, Stader D, Nguyen M, Cao D, McArthur R, Hoxhaj S. Perceptions of basic, advanced, and pediatric life support training in a United States medical school. J Emerg Med. 2014; 46(5): 695-700.

28. Shah A, Carter T, Kuwani T, Sharpe R. Simulation to develop tomorrow's medical registrar. Clin Teach. 2013; 10(1): 42-6.

29. Lake CL. Simulation in cardiothoracic and vascular anesthesia education: tool or toy? Semin Cardiothorac Vasc Anesth. 2005; 9: 265-73.

30. Wong AK. Full scale computer simulators in anesthesia training and evaluation. Can J Anaesth. 2004; 51: 455-64.

31. Newell B, Fibuch E, McCartney M. Simulation in anesthesiology: A key element in the new recertification process. Mo Med. 2013; 110(2): 139-41

32. Mclvor W, Burden A, Weinger MB, Steadman R. Simulation for maintenance of certification in anesthesiology: the first two years. J Contin Educ Health Prof Fall. 2012; 32(4): 236-42.

33. Byrne AJ, Greaves JD. Assessment instruments used during anaesthetic simulation: review of published studies. $\mathrm{Br} J$ Anaesth. 2001; 86: 445-50.

34. Hamstra SJ, Brydges R, Hatala R, Zendejas B, Cook DA. Reconsidering fidelity in simulation-based training. Acad Med. 2014; 89(3): 3873-92.

35. Schwid HA. Anesthesia simulators-technology and applications. Isr Med Assoc J. 2000; 2: 949-53.

36. Hartwell DA, Grayling M, Kennedy RR. Low-cost high-fidelity anaesthetic simulation. Anaesth Intensive Care. 2014; 42(3): 371-7.

37. Cumin D, Merry AF. Simulators for use in anaesthesia. Anaesthesia. 2007; 62: 151-62.

38. Hotchkiss MA, Mendoza SN. Update for nurse anesthetists. Part 6. Full-body patient simulation technology: gaining experience using a malignant hyperthermia model. AANA. J. 2001; 69: 5965 .

39. Davis DP, Buono C, Ford J, Paulson L, Koenig W, Carrison D. The effectiveness of a novel, algorithm-based difficult airway curriculum for air medical crews using human patient simulators. Prehosp Emerg Care. 2007; 11: 72-9
40. Lorello GR, Cook DA, Johnson RL, Brydges R. Simulation-based training in anaesthesiology: a systematic review and metaanalysis. Br J Anaesth. 2014; 112(2): 231-45.

41. Kulcsár Z, O'Mahony E, Lövquist E, Aboulafia A, Sabova D, Ghori K, et al. Preliminary evaluation of a virtual reality-based simulator for learning spinal anesthesia. J Clin Anesth. 2013; 25(2): 98-105.

42. Hu J, Lim YJ, Tardella N, Chang C, Warren L. Localized virtual patient model for regional anesthesia simulation training system. Stud Health Technol Inform. 2007;125: 185-90.

43. Struys MM, De Smet T, Mortier EP. Simulated drug administration: an emerging tool for teaching clinical pharmacology during anesthesiology training. Clin Pharmacol Ther. 2008;84:170-4.

44. Hassan Z, DiLorenzo A, Sloan P. Teaching clinical opioid pharmacology with the Human Patient Simulator. J Opioid Manag. 2010; 6(2): 125-32.

45. Bouillon TW. Hypnotic and opioid anesthetic drug interactions on the CNS, focus on response surface modeling. Handb Exp Pharmacol. 2008; 182: 471-87.

46. Schädler D, Heinrichs W, Mönk S, Elke G, Zick G, Scholz J. Simulation training for German anaesthesiologists - case scenarios and training results. Anasthesiol Intensivmed Notfallmed Schmerzther. 2008; 43: 474-7.

47. Park CS. Simulation and quality improvement in anesthesiology. Anesthesiol Clin. 2011; 29(1): 13-28.

48. ASA Workgroup on Simulation Education White Paper. ASA Approval of Anesthesiology Simulation Programs. Final Version July 18, 2006. Available from: http://education.asahq.org/sites/ education.asahq.org/files/users/1392/asasimwhitepaper.pdf

49. Clarke S, Horeczko T, Cotton D, Bair A. Heart rate, anxiety and performance of residents during a simulated critical clinical encounter: a pilot study. BMC Med Educ. 2014; 14(1): 153.

50. Bilotta FF, Werner SM, Bergese SD, Rosa G. Impact and implementation of simulation-based training for safety. Scientific WorldJournal. 2013; 7: 652956.

51. Han H, Resch DS, Kovach RA. Educational technology in medical education. Teach Learn Med. 2013;25 Suppl 1: S39-S43.

52. Michael M, Abboudi H, Ker J, Shamim Khan M, Dasgupta P, Ahmed K. Performance of technology-driven simulators for medical students-a systematic review. J Surg Res. 2014; 192(2): 531-43.

53. Ringel N, Bürmann BM, Fellmer-Drueg $E$, Roos $M$, Herzog W, Nikendei C. Integrated Peer Teaching of Communication and Clinical Skills How to Train Student Tutors? Psychother Psychosom Med Psychol. 2015 Mar 20. [Epub ahead of print] PMID: 25794354

54. Happel CS, Lease MA, Nishisaki A, Braga MS. Evaluating simulation education via electronic surveys immediately following live critical events: a pilot study. Hosp Pediatr. 2015; 5(2): $96-100$ 
55. Grall KH, Stoneking LR, DeLuca LA, Waterbrook AL, Pritchard TG, Denninghoff KR. An innovative longitudinal curriculum to increase emergency medicine residents' exposure to rarely encountered and technically challenging procedures. Adv Med Educ Pract. 2014; 5: 229-36.

56. Isaranuwatchai W, Brydges $R$, Carnahan H, Backstein D, Dubrowski A. Comparing the cost-effectiveness of simulation modalities: a case study of peripheral intravenous catheterization training. Adv Health Sci Educ Theory Pract. 2014; 19(2): 219-32.

57. Eason MP. Simulation devices in cardiothoracic and vascular anesthesia. Semin Cardiothorac Vasc Anesth. 2005; 9: 309-23.

58. Lussi C, Grapengeter M, Schüttler J. Simulator training in anesthesia. Applications and value. Anaesthesist. 1999; 48: 433-8.

Comment on this article:
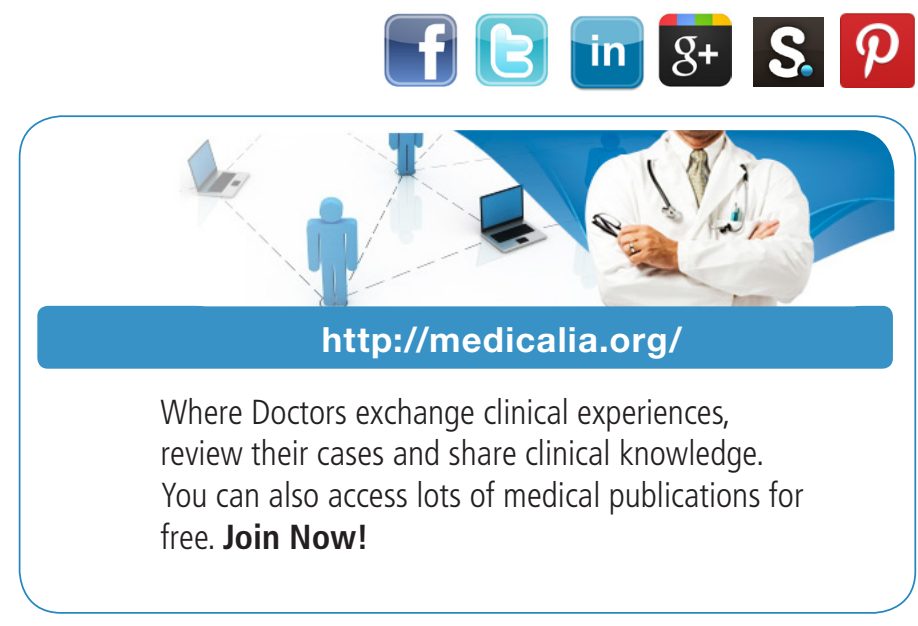

\section{Publish with iMedPub}

http://www.imed.pub

International Archives of Medicine is an open access journal publishing articles encompassing all aspects of medical science and clinical practice. IAM is considered a megajournal with independent sections on all areas of medicine. IAM is a really international journal with authors and board members from all around the world. The journal is widely indexed and classified Q1 in category Medicine. 